\title{
The effectiveness of intra-aortic balloon pump for myocardial infarction in patients with or without cardiogenic shock: a meta-analysis and systematic review
}

\author{
Xiao-yun Zheng*, Yi Wang, Yi Chen, Xi Wang, Lei Chen, Jun Li and Zhi-gang Zheng
}

\begin{abstract}
Background: Conflicting reports on the efficacy of intra-aortic balloon pump (IABP) during percutaneous coronary intervention (PCI) incited us to evaluate the utility of IABP in patients with acute myocardial infarction (AMI).

Methods: Randomized clinical trials comparing patients, who received IABP vs. control (no IABP) during PCI, were hand-searched from MEDLINE, Cochrane, and EMBASE databases using the terms "intra-aortic balloon pump, percutaneous coronary intervention, myocardial infarction, acute coronary syndrome". Mortality rate (30-day and 6-month mortality) was the primary outcome, while the secondary outcomes included 30-day bleeding rate, reinfarction rate, revascularization rate and stroke rate.

Results: Pooled results of the seven trials identified indicated that the 30-day and 6-month mortality rate were not significantly different between the IABP and control groups. However, in patients with MI, but without cardiogenic shock (CS), IABP was associated with lower odds of 30-day mortality $(\mathrm{OR}=0.35, p=0.015)$ and 6 -month mortality $(\mathrm{OR}=0.41, p=0.020)$. The pooled results of 30 -day bleeding rate was not significantly higher in patients with IABP than the control group, but for the patients with high risk $\mathrm{PCI}$ without $\mathrm{CS}$, it was higher in patients with IABP than the control group $(\mathrm{OR}=1.58, p=0.009)$. The re-infarction, revascularization, and the stroke rate at 30 days of follow-up were not significantly different between the two groups.

Conclusions: The present results do not favor the clinical utility of IABP in patients suffering high-risk PCI without CS and AMI complicated with CS. However, in patients with AMI, but without CS, IABP may reduce the 30-day and 6-month mortality rate.
\end{abstract}

Keywords: Myocardial infarction, Percutaneous coronary intervention, Intra-aortic balloon pump

\section{Background}

Acute myocardial infarction (AMI) complicated by cardiogenic shock (CS) is one of the leading causes of death in patients hospitalized with AMI, and it accounts for $41.1 \%$ of overall in-hospital mortality in a populationbased study [1, 2]. Intra-aortic balloon pump (IABP) is the most widely used mechanical device for the treatment of AMI [3, 4], since its introduction by Kantrowitz and colleagues in early 1960s [5]. The International Benchmark Registry (250 US and non-US centers) of

\footnotetext{
* Correspondence: atfcn@126.com

Department of Senior Official Ward, China-Japan Friendship Hospital, 2

Yinghua Dongjie, Beijing 100029, China
}

22,633 AMI patients treated with IABP suggested that $19 \%$ of IABP implantation were for cardiogenic shock, $19.9 \%$ for angiography and angioplasty, and $14.6 \%$ as an adjunct (pre-operative) to high-risk coronary artery bypass grafting [6]. IABP support effectively reduces the left ventricular wall stress and myocardial demand, increases the coronary perfusion pressure, stroke volume, cardiac output, and ameliorates ischemia, making it a potentially valuable therapy in CS $[3,7,8]$. Reports elsewhere suggest that IABP offers a substantial advantage when used in combination with thrombolytic therapy $[9,10]$. In a previous study, the use of IABP in conjunction with thrombolytic therapy decreased the odds of

(c) 2016 The Author(s). Open Access This article is distributed under the terms of the Creative Commons Attribution 4.0 International License (http://creativecommons.org/licenses/by/4.0/, which permits unrestricted use, distribution, and reproduction in any medium, provided you give appropriate credit to the original author(s) and the source, provide a link to the Creative Commons license, and indicate if changes were made. The Creative Commons Public Domain Dedication waiver (http://creativecommons.org/publicdomain/zero/1.0/) applies to the data made available in this article, unless otherwise stated. 
death by $18 \%$ [9]. In addition, IABP has been widely used in the prevention of adverse catheter laboratory events during elective high-risk PCI [11].

Despite its frequent use in the clinical practice for the treatment of AMI, recent reports dispute whether intraaortic balloon counterpulsation provide any incremental benefit to reperfusion therapy $[9,10,12,13]$. In patients with AMI and CS, the evidence in favor of IABP is currently limited to registry data and retrospective analyses, and small, prospective studies without any reliable mortality data [14]. A recent systematic review and metaanalysis comparing IABP versus no IABP in patients with AMI and CS concluded that the available data did not provide a convincing evidence for either benefit or harm to support the use of IABP counterpulsation [8]. According to the 2011 guidelines released by the American College of Cardiology Foundation (ACCF) and American Heart Association (AHA), IABP counterpulsation is reasonable in non-ST-elevation myocardial infarction (NSTEMI) patients for severe ischemia that is continuing or recurs frequently despite medical therapy, for hemodynamic instability in patients before or after coronary angiography, and for mechanical complications of MI [15]. In 2013, ACCF/AHA has released an updated guideline for patients with STEMI, where the recommendation for the placement of IABP in CS was downgraded from Class I to Class IIa, because of the lack of clear superiority in clinical benefit and reduction of mortality $[16,17]$. Similarly, IABP was recommended in ST-elevation myocardial infarction (STEMI) patients with CS by the European Society of Cardiology in 2008 but an updated guideline released by European Society of Cardiology (ESC) and the European Association for Cardio-Thoracic Surgery (EACTS) in 2014 did not recommend routinely using IABP in patients with CS $[18,19]$.

Use of elective IABP support in patients undergoing high-risk $\mathrm{PCI}$ is still debatable. The evidence suggests that routine IABP use does not provide clinical benefit in patients undergoing high-risk procedures or those with AMI in the absence of CS, but it causes a relative reduction in the long-term all-cause mortality [11]. Bahekar and colleagues also indicated that while IABP is not beneficial in high-risk AMI patients without cardiogenic shock, there was significant reduction in mortality with IABP in patients having AMI with cardiogenic shock [20].

Considering the contrasting reports in the field and the necessity for unified guidelines for the use of IABP, it is of utmost importance to evaluate the clinical relevance of IABP as an adjunct therapy to PCI in patients with acute myocardial infarction with or without CS. The present meta-analysis evaluated the clinical outcomes of IABP as an adjunct therapy during PCI as opposed to PCI alone. The outcomes examined include, 30-day mortality, 6-month mortality, 30-day reinfarction rate, 30 -day revascularization rate, 30-day stroke rate, and 30-day bleeding rate.

\section{Methods \\ Search strategy}

The current meta-analysis was conducted in accordance with the PRISMA guidelines [21]. We performed a literature search of the Pubmed, Medline, Cochrane, and EMBASE databases until December 31, 2015 using the key words, "intra-aortic balloon pump, percutaneous coronary intervention, myocardial infarction, acute coronary syndrome, and unstable angina". The reference lists of relevant studies were also hand-searched.

\section{Selection criteria}

Only randomized clinical trials in adult patient populations ( $\geqq 18$ years), who received PCI were included in the present meta-analysis. The intervention group received IABP during PCI, while the control group did not.

We excluded studies that are not-randomized controlled trials and those with no reported quantitative primary or secondary outcomes. Non-English articles, and nonoriginal articles, including letters, comments, editorials, case reports, technical reports, and personal communications were also excluded from the analysis.

\section{Study selection and data extraction}

Studies were identified by the search strategy by two independent reviewers. Where there was uncertainty regarding eligibility, a third reviewer was consulted.

Data extraction was also performed by two independent reviewers, and a third reviewer was consulted to resolve any discord. The following information was extracted from studies that met the inclusion criteria: the name of the first author, year of publication, study design, demographic data of subjects, patient diagnosis, prior medical history, type of intervention, and numerical data on outcomes of interest. The primary outcome analyzed was mortality rate (30-day mortality, 6-month mortality) while the secondary outcomes included 30-day bleeding rate, 30-day re-infarction rate, 30-day revascularization rate and 30-day stroke rate.

\section{Assessment of risk of bias}

We utilized using the Cochrane Risk of Bias Tool to assess the included studies [22]. The quality assessment was performed by two independent reviewers and a third reviewer was consulted for any uncertainties.

\section{Statistical analysis}

For each outcome analyzed, the odds ratio (OR) with $95 \%$ confidence interval (CI) was calculated. Heterogeneity among the studies was assessed by the Cochran's Q 
test and the $\mathrm{I}^{2}$ statistic. For Cochran's $\mathrm{Q}, p<0.10$ indicated statistically significant heterogeneity. For the $\mathrm{I}^{2}$ statistic, which indicates the percentage of the observed between-study variability due to heterogeneity rather than chance, heterogeneity was categorized as follows: no heterogeneity, $\mathrm{I}^{2}=0-25 \%$; moderate heterogeneity, $\mathrm{I}^{2}=25-50 \%$; large heterogeneity, $\mathrm{I}^{2}=50-75 \%$; and extreme heterogeneity, $\mathrm{I}^{2}=75-100 \%$. All analyses were stratified according to subgroups based on patients' risk factor profile (i.e., high-risk PCI without CS, MI with CS, and MI without CS). First, pooled ORs for each outcome within each group were calculated by the randomeffects model of analysis (DerSimonian-Laird method) by assuming commonality in between-study variance across subgroups. Then, a random-effect model was performed to combine the estimates across subgroups. A two-sided $p$ value $<0.05$ was considered to indicate statistical significance. Sensitivity analysis was performed for the primary outcome, short-term mortality rate, based on the leave-one-out approach. Publication bias was assessed by constructing a funnel plot for primary outcome and using the Egger's test. The absence of publication bias is indicated by the data points forming a symmetrical, funnel-shaped distribution and $p>0.05$, as determined by the Egger's test. All statistical analyses were performed using the statistical software, Comprehensive Meta-Analysis, version 2.0 (Biostat, Englewood, NJ, USA).

\section{Results}

\section{Literature search}

The flowchart for the selection of trials is outlined in Fig. 1. Of the 113 articles identified through the literature search, 87 were excluded, and the remaining 26 articles were assessed for full text reviewing. After full text reviewing, we excluded 17 articles for various reasons, including having no outcome of interest, the details of which are represented in Fig. 1. The present meta-analysis comprises seven randomized controlled trials reported in nine articles, which were included for the following qualitative and quantitative analysis [12, 13, 23-29].

\section{Study characteristics and outcomes}

A total of seven randomized controlled trials were included in the meta-analysis. The characteristics of these studies are summarized in Table 1. Across the studies, the total numbers of patients ranged from 19 to 301 in the IABP group, while it ranged from 21 to 299 in the control (without IABP) group. Two studies (in three

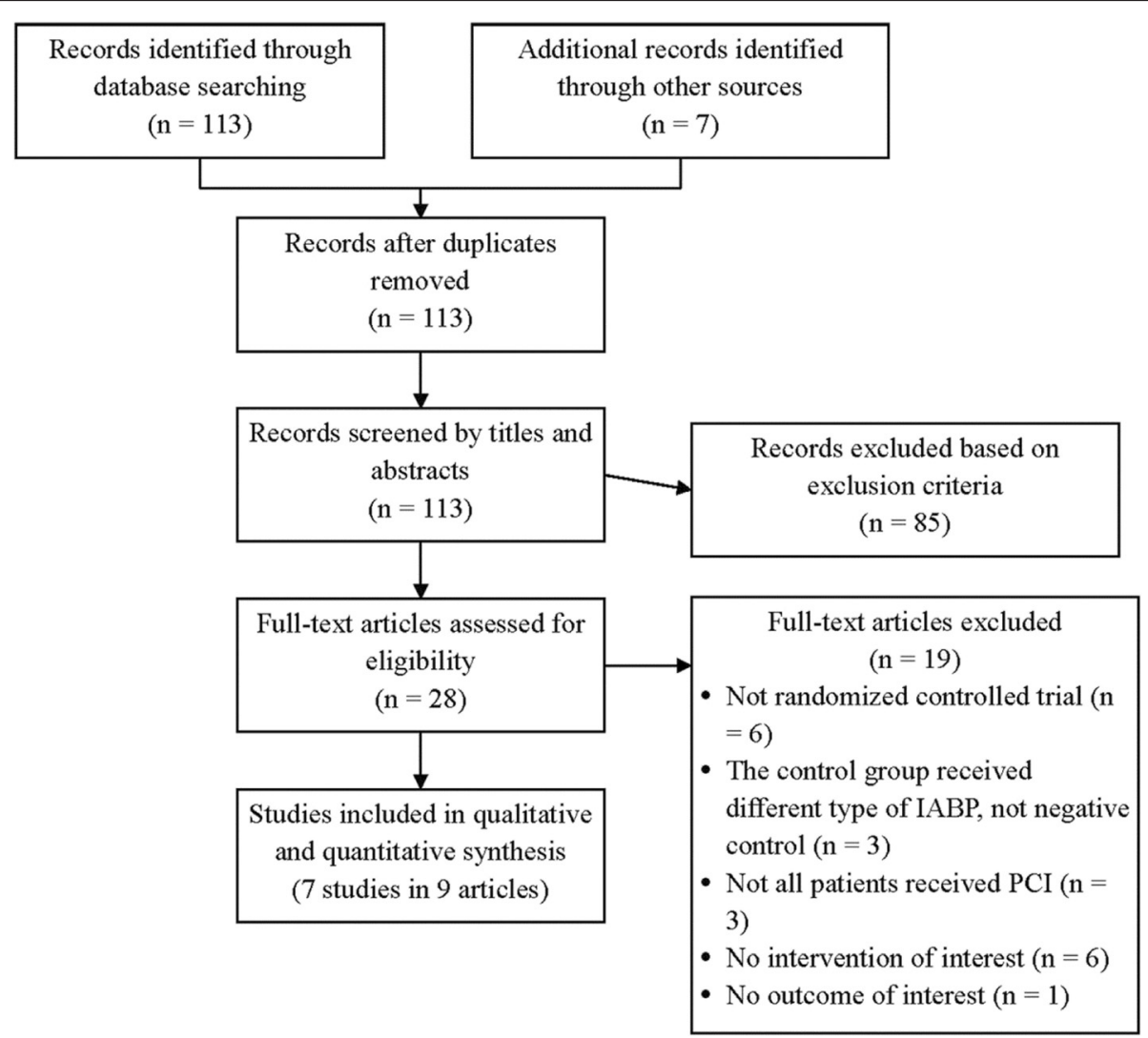

Fig. 1 Flowchart of study selection. IABP, intra-aortic balloon pump; PCl: percutaneous coronary intervention 
Table 1 Summary of baseline characteristics of included studies in meta-analysis

\begin{tabular}{|c|c|c|c|c|c|c|c|c|c|c|c|}
\hline Authors (Year) & Trial name & Comparison & $\begin{array}{l}\text { Number of } \\
\text { patients }\end{array}$ & Age (years) & Male (\%) & Clinical symptom & Hypertension & Prior Ml & Prior PCl & Prior CABG & Prior stroke \\
\hline \multirow{2}{*}{$\begin{array}{l}\text { Thiele }(2012,2013) \\
{[12,13]}\end{array}$} & \multirow[t]{2}{*}{ |ABP-SHOCK || } & IABP & 301 & $70(58,78)^{a}$ & 67.1 & \multirow{2}{*}{$\begin{array}{l}\text { Ml complicated } \\
\text { by CS }\end{array}$} & 213/296 (72.0 \%) & 71/300 (23.7 \%) & 63/299 (21.1 \%) & 20/300 (6.7 \%) & $24 / 300(8.0 \%)$ \\
\hline & & without IABP & 299 & $69(58,76)^{\mathrm{a}}$ & 70.6 & & 199/299 (66.6 \%) & 61/299 (20.4 \%) & 52/299 (17.4)\% & $12 / 299(4.0 \%)$ & 20/299 (6.7\%) \\
\hline \multirow[t]{2}{*}{ Gu (2011) [24] } & \multirow[t]{2}{*}{-} & IABP & 51 & $67.4(9.6)$ & 56.9 & \multirow{2}{*}{$\begin{array}{l}\text { Acute STEMI or non- } \\
\text { STEMI without CS }\end{array}$} & 35 (68.6\%) & 2 (3.9\%) & NR & NR & NR \\
\hline & & without IABP & 55 & $66.6(8.0)$ & 65.5 & & $33(60.0 \%)$ & $3(5.5 \%)$ & NR & NR & NR \\
\hline \multirow[t]{2}{*}{ Patel (2011) [23] } & \multirow[t]{2}{*}{ CRISP AMI } & IABP & 161 & $56.1(48.3,64.3)^{a}$ & 82.0 & \multirow{2}{*}{$\begin{array}{l}\text { Acute STEMI } \\
\text { without CS }\end{array}$} & 39 (24.2 \%) & NR & $3(1.9 \%)$ & NR & 0 \\
\hline & & without IABP & 176 & $57.7(48.6,66.4)^{a}$ & 81.8 & & 60 (34.1\%) & NR & $2(1.1 \%)$ & NR & $1(0.6 \%)$ \\
\hline \multirow{2}{*}{$\begin{array}{l}\text { Perera }(2010,2013) \\
{[26,27]}\end{array}$} & \multirow[t]{2}{*}{ BCIS-1 } & IABP & 151 & $71(9)$ & 81 & \multirow{2}{*}{$\begin{array}{l}\text { High risk } \mathrm{PCl} \\
\text { without } \mathrm{CS}\end{array}$} & $95(63 \%)$ & $113(75 \%)$ & 17 (11\%) & 25 (17\%) & $12(8 \%)$ \\
\hline & & without IABP & 150 & $71(10)$ & 78 & & $91(61)$ & $108(73 \%)$ & $14(9 \%)$ & $20(13 \%)$ & $11(7 \%)$ \\
\hline \multirow{2}{*}{$\begin{array}{l}\text { Prondzinsky } \\
\text { (2010) [28] }\end{array}$} & \multirow[t]{2}{*}{ IABP SHOCK } & IABP & 19 & $62.1(38,82)^{b}$ & 74 & \multirow{2}{*}{$\begin{array}{l}\text { Acute MI } \\
\text { complicated } \\
\text { by CS }\end{array}$} & $8(42.1 \%)$ & $4(21.1 \%)$ & NR & NR & NR \\
\hline & & without IABP & 21 & $66.1(49,82)^{b}$ & 81 & & $10(47.6 \%)$ & $5(23.8 \%)$ & NR & NR & NR \\
\hline \multirow[t]{2}{*}{ van't Hof (1999) [29] } & \multirow[t]{2}{*}{-} & IABP & 118 & $59(10)$ & 84 & \multirow{2}{*}{$\begin{array}{l}\text { High risk } \mathrm{PCl} \\
\text { without } \mathrm{CS}\end{array}$} & NR & 17 (14 \%) & NR & $3(3 \%)$ & NR \\
\hline & & without IABP & 120 & $56(11)$ & 84 & & NR & 16 (13 \%) & NR & 7 (6 \%) & NR \\
\hline \multirow[t]{2}{*}{ Stone (1997) [25] } & \multirow[t]{2}{*}{ PAMI-II TRIAL } & IABP & 211 & 64.7 (11.9) & 74.9 & \multirow{2}{*}{$\begin{array}{l}\text { High risk Ml } \\
\text { without CS }\end{array}$} & 116 (54.8 \%) & 45 (21.4 \%) & NR & 16 (7.5 \%) & NR \\
\hline & & without IABP & 226 & $63.7(13.0)$ & 75.2 & & $126(55.7 \%)$ & 49 (21.7\%) & NR & $13(5.9 \%)$ & NR \\
\hline
\end{tabular}

Abbreviations: IABP intra-aortic balloon pump, CS cardiogenic shock, MI myocardial infarction, STEMI ST-elevation MI, PCI percutaneous coronary intervention, CABG coronary artery bypass graft, NR no reported Data presented in mean (SD), median (IQR) ${ }^{\text {, }}$, or mean (range) 
articles) were designed for patients with AMI complicated by CS $[12,13,28]$, while two studies included patients with acute ST-elevation or non-ST-elevation myocardial infarction without CS [23, 24]. The remaining three studies (in four articles) were designed for high risk patients with MI without CS [25-27, 29].

Outcomes of the trials are shown in Table 2. The 30-day mortality rate ranged from 1.9 to $39.7 \%$ in the IABP group, whereas, it ranged from 0.7 to $41.3 \%$ in the control group. Similarly, the IABP group had a 6-month mortality rate of 1.9 to $48.7 \%$, while it was 5.2 to $49.2 \%$ in the no IABP group. Patients in the IABP group demonstrated a 30-day re-infarction rate of 2 to $12.6 \%$, a 30-day revascularization rate of 0.7 to $20 \%$, a 30-day stroke rate of 0.7 to $2.4 \%$, and a 30 -day bleeding rate of 3.1 to $36.0 \%$. Whereas, the control, no IABP group showed a 30-day reinfarction rate of 1.3 to $13.3 \%$, a 30 -day revascularization rate of 1.8 to $22 \%$, a 30-day stroke rate of 0 to $1.7 \%$, and a 30-day bleeding rate of 1.7 to $27.4 \%$ (Table 2).

\section{Meta-analysis}

\section{Primary outcome: 30-day mortality rate and 6-month} mortality rate

One study [29] was excluded from the analysis, because it had not reported a 30-day mortality rate. There was no evidence of significant heterogeneity when data from the remaining six studies were pooled $(\mathrm{Q}=7.4$, $\left.p=0.192 ; \mathrm{I}^{2}=32.5 \%\right)$. The overall analysis revealed that the 30-day mortality rate was not significantly different in patients with IABP, as compared to patients without IABP $(\mathrm{OR}=0.82,95 \% \mathrm{CI}=0.38$ to $1.75, \mathrm{Z}=-0.52, p=0.605)$ (Fig. 2a). In patients with MI, but without CS, the likelihood of 30-day mortality was significantly lower in patients with IABP than in those without IABP $(\mathrm{OR}=0.35$, $95 \% \mathrm{CI}=0.15$ to $0.82, \mathrm{Z}=-2.42, p=0.015$ ) (Fig. $2 \mathrm{a}$ ).

Two studies $[25,28]$ were excluded from the final analysis as they did not report the 6-month mortality rate. There was no evidence of significant heterogeneity when data from the five studies were pooled $(\mathrm{Q}=4.4, p=0.200$; $\mathrm{I}^{2}=33.2 \%$ ) (Fig. 2b). The overall analysis revealed that the 6-month mortality rate was not significantly different in patients with IABP, as opposed to those without IABP $(\mathrm{OR}=0.78,95 \% \mathrm{CI}=0.45$ to $1.33, \mathrm{Z}=-0.93, p=0.354)$. Similarly, in patients with MI, but without CS, IABP was associated with lower odds of 6-month mortality $(\mathrm{OR}=0.41,95 \% \mathrm{CI}=0.19$ to $0.87, \mathrm{Z}=-2.324, p=0.020)$ (Fig. 2b).

\section{Secondary outcomes}

30-day bleeding rate Two studies [28, 29] were excluded from the analysis as there was no report on the 30 -day bleeding rate. There was no evidence of significant heterogeneity when data from the five studies were pooled $(\mathrm{Q}=5.0, p=0.288 ; \mathrm{I} 2=19.9 \%$ ) (Table 3).

Table 2 Summary of outcomes of included studies in meta-analysis

\begin{tabular}{|c|c|c|c|c|c|c|c|c|}
\hline Authors (Year) & Comparison & $\begin{array}{l}\text { Number of } \\
\text { patients }\end{array}$ & $\begin{array}{l}\text { 30-day } \\
\text { mortality }\end{array}$ & $\begin{array}{l}\text { 6-month } \\
\text { mortality }\end{array}$ & $\begin{array}{l}\text { 30-day } \\
\text { reinfarction rate }\end{array}$ & $\begin{array}{l}\text { 30-day } \\
\text { revascularization rate }\end{array}$ & $\begin{array}{l}\text { 30-day } \\
\text { stroke rate }\end{array}$ & $\begin{array}{l}\text { 30-day } \\
\text { bleeding rate }\end{array}$ \\
\hline \multirow{2}{*}{$\begin{array}{l}\text { Thiele }(2012,2013) \\
{[12,13]}\end{array}$} & IABP & 301 & $39.7 \%$ & $48.7 \%$ & $3.0 \%$ & $20 \%$ & $0.7 \%$ & $20.7 \%$ \\
\hline & $\begin{array}{l}\text { without } \\
\text { IABP }\end{array}$ & 299 & $41.3 \%$ & $49.2 \%$ & $1.3 \%$ & $22 \%$ & $1.7 \%$ & $20.8 \%$ \\
\hline \multirow[t]{2}{*}{ Gu (2011) [24] } & IABP & 51 & $9.8 \%$ & $17.6 \%$ & $2.0 \%$ & $3.9 \%$ & NR & $11.8 \%$ \\
\hline & $\begin{array}{l}\text { without } \\
\text { IABP }\end{array}$ & 55 & $27.3 \%$ & $32.7 \%$ & $3.6 \%$ & $1.8 \%$ & NR & $3.6 \%$ \\
\hline \multirow[t]{2}{*}{ Patel (2011) [23] } & IABP & 161 & $1.9 \%$ & $1.9 \%$ & NR & NR & $1.9 \%$ & $3.1 \%$ \\
\hline & $\begin{array}{l}\text { without } \\
\text { IABP }\end{array}$ & 176 & $4.0 \%$ & $5.2 \%$ & NR & NR & $0.6 \%$ & $1.7 \%$ \\
\hline \multirow{2}{*}{$\begin{array}{l}\text { Perera }(2010,2013) \\
{[26,27]}\end{array}$} & $\mathrm{IABP}$ & 151 & $2.0 \%$ & $4.6 \%$ & $12.6 \%$ & $0.7 \%$ & $1.3 \%$ & $19.2 \%$ \\
\hline & $\begin{array}{l}\text { without } \\
\text { IABP }\end{array}$ & 150 & $0.7 \%$ & $7.4 \%$ & $13.3 \%$ & $2.7 \%$ & 0 & $11.3 \%$ \\
\hline \multirow{2}{*}{$\begin{array}{l}\text { Prondzinsky (2010) } \\
\text { [28] }\end{array}$} & IABP & 19 & $36.8 \%$ & NR & NR & NR & NR & NR \\
\hline & $\begin{array}{l}\text { without } \\
\text { IABP }\end{array}$ & 21 & $28.6 \%$ & NR & NR & NR & NR & NR \\
\hline \multirow{2}{*}{$\begin{array}{l}\text { van't Hof (1999) } \\
\text { [29] }\end{array}$} & IABP & 118 & NR & $10 \%$ & NR & NR & NR & NR \\
\hline & $\begin{array}{l}\text { without } \\
\text { IABP }\end{array}$ & 120 & NR & $8 \%$ & NR & NR & NR & NR \\
\hline \multirow[t]{2}{*}{ Stone (1997) [25] } & IABP & 211 & $4.3 \%$ & NR & $6.2 \%$ & $4.7 \%$ & $2.4 \%$ & $36.0 \%$ \\
\hline & $\begin{array}{l}\text { without } \\
\mathrm{IABP}\end{array}$ & 226 & $3.1 \%$ & NR & $8.0 \%$ & $4.0 \%$ & 0 & $27.4 \%$ \\
\hline
\end{tabular}




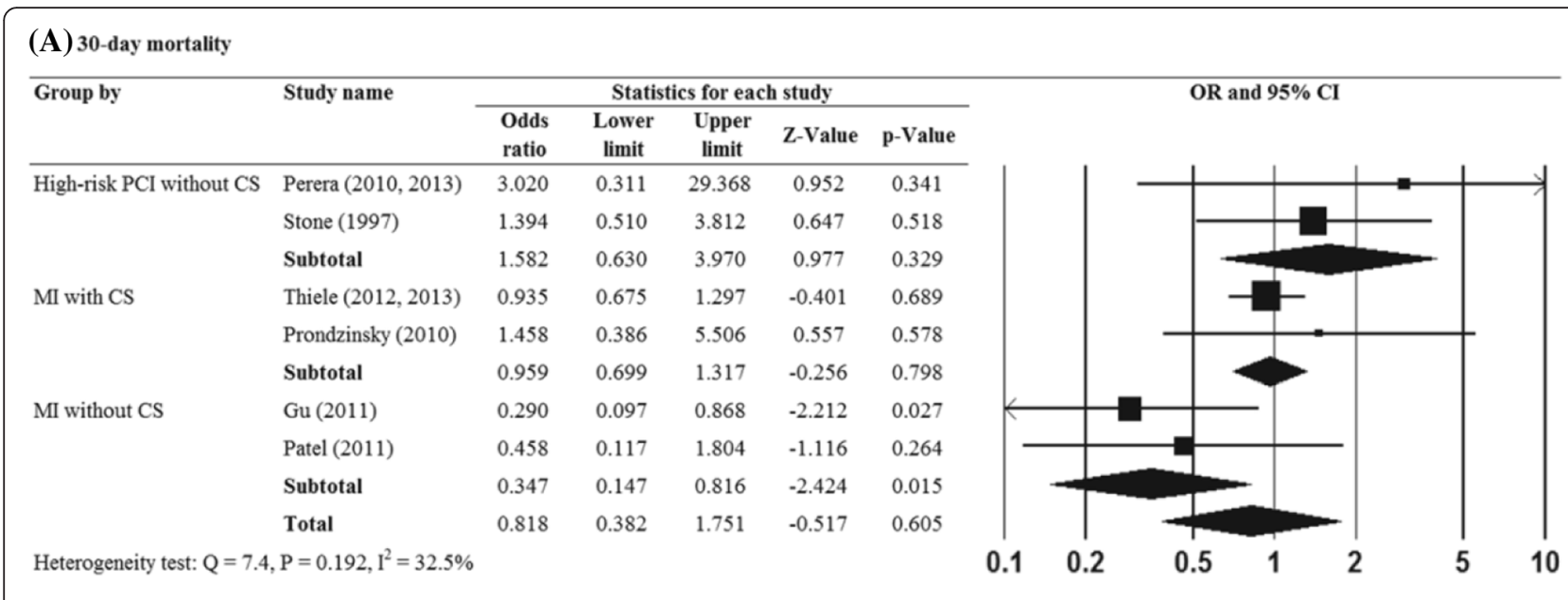

\section{(B) 6-month mortality}

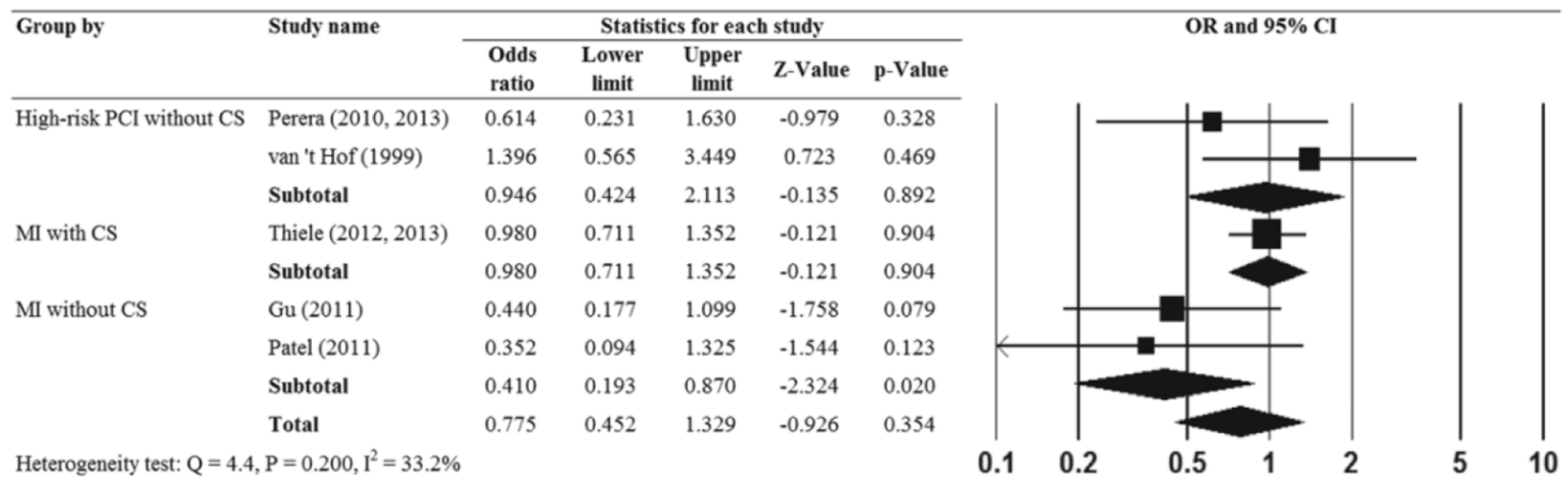

Fig. 2 Forest plots showing the results for the meta-analysis of (a) 30-day mortality rate, (b) 6-month mortality rate. Abbreviations: IABP, intra-aortic balloon pump; $\mathrm{Cl}$, confidence interval

The overall analysis revealed that the 30-day bleeding rate was significantly higher in patients with IABP compared to those without IABP $(\mathrm{OR}=1.39,95 \% \mathrm{CI}=0.86$ to 2.24 , $\mathrm{Z}=1.36, p=0.174)$. The results of subgroup analysis showed that patients with IABP had higher odds of 30-day bleeding than those without IABP in the subgroup of high-risk PCI without $\mathrm{CS}(\mathrm{OR}=1.59,95 \% \mathrm{CI}=1.12$ to 2.24, $\mathrm{Z}=2.63, p=0.009$ ) (Table 3 ).

30-day reinfarction rate Three studies $[23,28,29]$ were excluded from the analysis, since a 30-day re-infarction rate was not reported. There was no evidence of significant heterogeneity when data from the remaining four studies were pooled $\left(\mathrm{Q}=2.64, p=0.450 ; \mathrm{I}^{2}=0 \%\right)$. The overall analysis revealed that the 30 -day reinfarction rate was not significantly different in patients with IABP as compared to patients without IABP $(\mathrm{OR}=0.96,95 \% \mathrm{CI}=$ 0.61 to $1.51, Z=-0.16, p=0.875)$. No significant results were observed in the subgroup analysis according to the patients' risk factor profile (Table 3). 30-day revascularization rate Three studies [23, 28, 29] were excluded from the analysis as the 30-day revascularization rate was not reported. There was no evidence of significant heterogeneity when data from the four studies were pooled $\left(\mathrm{Q}=2.23, p=0.526 ; \mathrm{I}^{2}=0 \%\right)$. The overall analysis revealed that the 30-day revascularization rate was not significantly different between the two groups (IABP vs. control, no IABP) ( $\mathrm{OR}=0.90,95 \% \mathrm{CI}=0.54$ to $1.51, Z=-0.40, p=0.688$ ). No significant results were found in the subgroup analysis based on patients' risk factor profile (Table 3).

30-day stroke rate Three studies [24, 28, 29] were excluded from the final analysis as no data on 30-day stroke rate was reported. There was no evidence of significant heterogeneity when data from the remaining four studies were pooled $\left(\mathrm{Q}=5.59, p=0.133 ; \mathrm{I}^{2}=46.3 \%\right)$. The overall analysis revealed that the 30-day stroke rate was not significantly different in patients with IABP as compared to those without IABP $(\mathrm{OR}=1.58,95 \% \mathrm{CI}=0.51$ to 4.86 , 
Table 3 Results of meta-analysis for secondary outcomes

\begin{tabular}{llll}
\hline Outcomes & No. of studies & OR $(95 \%$ Cl $)$ & $P$ \\
\hline 30-day bleeding & & & \\
High-risk PCl without CS & 2 & $1.585(1.124,2.235)$ & $0.009^{*}$ \\
MI with CS & 1 & $0.992(0.668,1.472)$ & 0.967 \\
MI without CS & 2 & $2.451(0.826,7.273)$ & 0.106 \\
Total & 5 & $1.391(0.864,2.238)$ & 0.174 \\
30-day reinfarction rate & & & \\
High-risk PCl without CS & 2 & $0.851(0.517,1.400)$ & 0.525 \\
MI with CS & 1 & $2.273(0.692,7.464)$ & 0.176 \\
MI without CS & 1 & $0.530(0.047,6.028)$ & 0.609 \\
Total & 4 & $0.964(0.614,1.514)$ & 0.875 \\
30-day revascularization rate & & \\
High-risk PCI without CS & 2 & $0.749(0.180,3.118)$ & 0.691 \\
MI with CS & 1 & $0.883(0.501,1.554)$ & 0.665 \\
MI without CS & 1 & $2.204(0.194,25.071)$ & 0.524 \\
Total & 4 & $0.900(0.538,1.505)$ & 0.688 \\
30-day stroke rate & & & \\
High-risk PCI without CS & 2 & $7.959(0.974,65.021)$ & 0.053 \\
MI with CS & 1 & $0.393(0.076,2.043)$ & 0.267 \\
MI without CS & 1 & $3.323(0.342,32.271)$ & 0.301 \\
Total & 4 & $1.576(0.511,4.861)$ & \\
\hline A & & &
\end{tabular}

Abbreviations: CS cardiogenic shock, $M I$ myocardial infarction ${ }^{*} P<0.05$
$Z=0.79, p=0.428)$. No significant results were found in the subgroup analysis according to the patient risk factor profile (Table 3).

\section{Sensitivity analysis}

The results of the meta-analysis using the leave-one-out approach to assess sensitivity is summarized in Fig. 3a (30-day mortality) and Fig. 3b (6-month mortality). For 30-day bleeding rate, 30-day reinfarction rate, 30-day revascularization rate, and 30-day stroke rate, results were not shown. The direction and magnitude of the pooled estimates for 30-day mortality and 6-month mortality did not vary considerably, indicating that the metaanalysis had good reliability.

\section{Publication bias}

There was no evidence of significant publication bias for the 30-day mortality rate as assessed by the Egger's test (Fig. 4). The results reveal no publication bias for the 30-day mortality rate $(p=0.472)$. Publication bias was not assessed for the other five outcomes, because more than five studies are required to detect funnel plot asymmetry [30].

\section{Assessment of risk of bias}

The results of the assessments of risk of bias are presented in Fig. 5. The risk of potential bias of individual

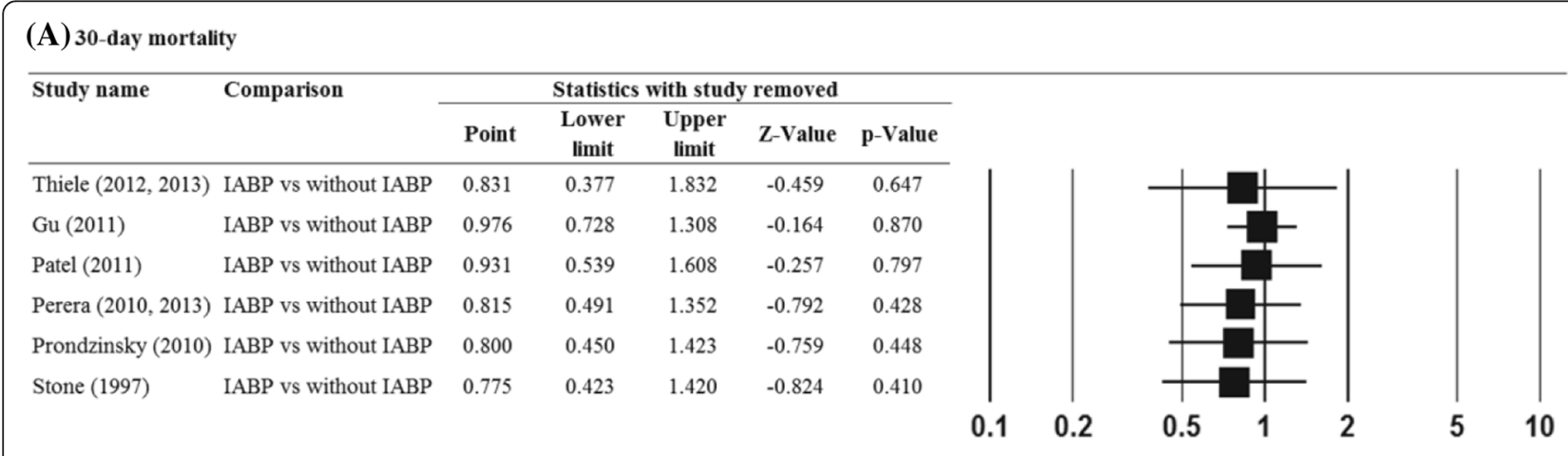

(B) 6-month mortality

\begin{tabular}{|c|c|c|c|c|c|c|c|c|c|c|c|c|c|}
\hline \multirow[t]{2}{*}{ Study name } & \multirow[t]{2}{*}{ Comparison } & \multicolumn{5}{|c|}{ Statistics with study removed } & & & & & & & \\
\hline & & Point & $\begin{array}{c}\text { Lower } \\
\text { limit }\end{array}$ & $\begin{array}{c}\text { Upper } \\
\text { limit }\end{array}$ & Z-Value & p-Value & & & & & & & \\
\hline Thiele $(2012,2013)$ & IABP vs without IABP & 0.646 & 0.355 & 1.178 & -1.425 & 0.154 & & & & & & & \\
\hline $\mathrm{Gu}(2011)$ & IABP vs without IABP & 0.897 & 0.610 & 1.318 & -0.554 & 0.579 & & & & & & & \\
\hline Patel (2011) & IABP vs without IABP & 0.857 & 0.573 & 1.280 & -0.755 & 0.451 & & & & & & & \\
\hline Perera $(2010,2013)$ & IABP vs without IABP & 0.790 & 0.468 & 1.333 & -0.884 & 0.377 & & & & & & & \\
\hline van 't Hof (1999) & IABP vs without IABP & 0.681 & 0.415 & 1.118 & -1.517 & 0.129 & & & & & & & \\
\hline & & & & & & & 0.1 & 0.2 & 0.5 & 1 & 2 & 5 & 10 \\
\hline
\end{tabular}

Fig. 3 Results of sensitivity analysis to examine the influence of individual studies on pooled estimates as determined using the leave-one-out approach: (a) 30-day mortality rate, (b) 6-month mortality rate. Abbreviations: IABP, intra-aortic balloon pump; Cl, confidence interval 


\section{Funnel Plot of Standard Error by Log odds ratio}

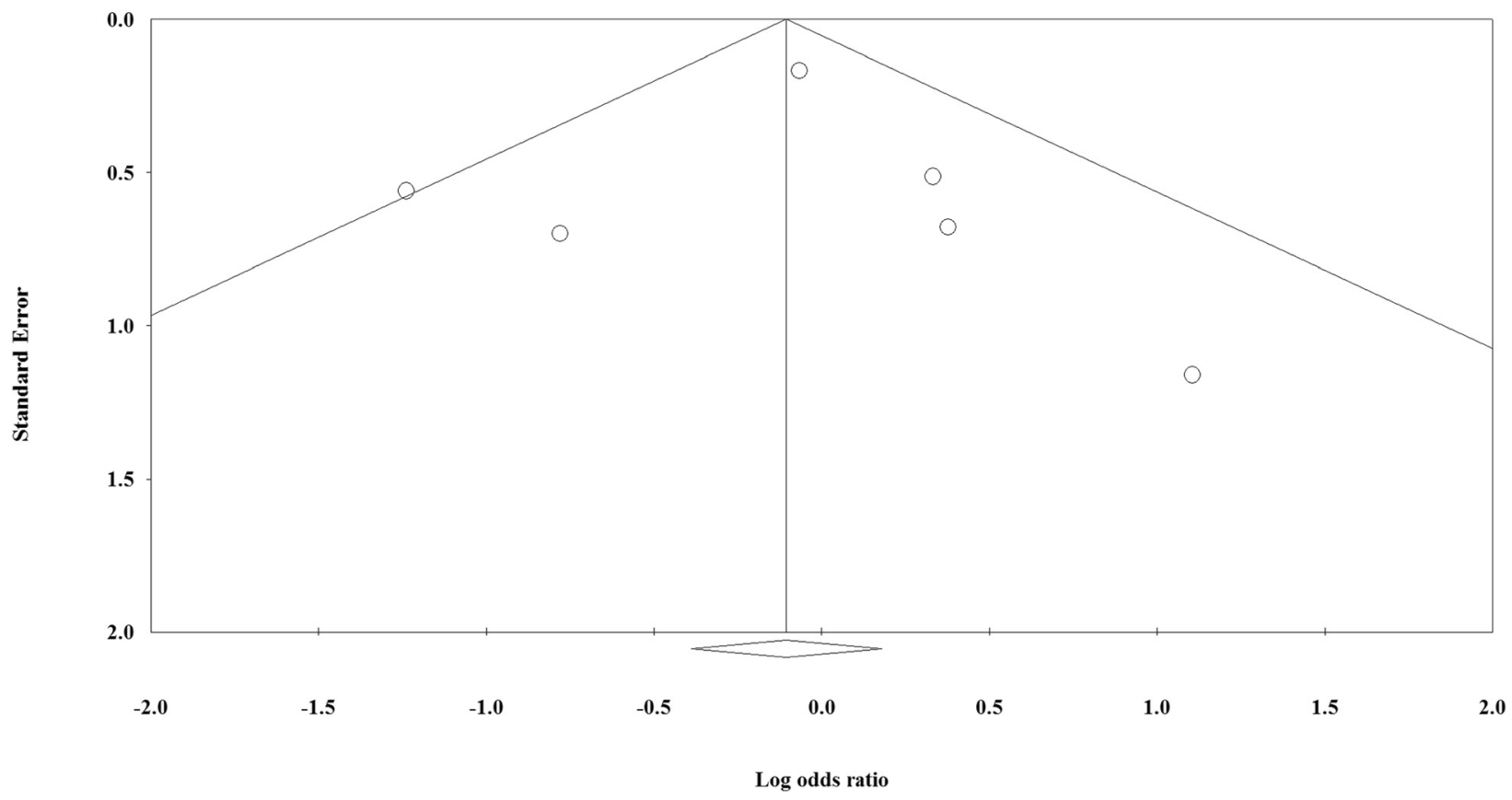

Fig. 4 Funnel plot for publication bias for 30-day mortality. White circles represent observed studies. White rhombuses represent observed combined effect size

studies is given in Fig. 5a, while the risk of bias of all included studies is represented in Fig. $5 \mathrm{~b}$. The bias in the results can be mainly attributed to the performance bias, because none of the included studies could blind the patients or the study personnel in-charge.

\section{Discussion}

IABP increase diastolic aortic pressure, which improves the diastolic coronary flow. IABP simultaneously reduces systolic aortic pressure, which in turn decrease the afterload and oxygen consumption of the myocardium $[3,8,29]$. In addition to AMI, IABP has been widely used in indications including, CS, high risk percutaneous coronary intervention and cardiac surgery for hemodynamic support $[3,14]$. Besides its long-standing clinical use as the main form of mechanical circulatory support, the longterm benefits of IABP are still controversial due to the paucity of prospective, randomized clinical trials [14]. The current study was undertaken to broaden our understanding through a systematic review and meta-analysis of the existing literature in the clinical practice of IABP in terms of AMI with/without CS as well as in patients with high risk PCI. The pooled results of the current meta-analysis do not favor the overall survival and hence, the clinical utility of IABP, in patients suffering high-risk PCI without CS and AMI complicated with CS. However, for patients with MI but without CS, IABP may reduce 30-day and 6-month mortality rate.
CS is a clinical state of hypoperfusion characterized by a systolic pressure, $90 \mathrm{mmHg}$ and a central filling pressure (wedge pressure), $.20 \mathrm{mmHg}$, or a cardiac index,1.8 L/ $\mathrm{min} / \mathrm{m} 2$, and caused by the extensive loss of viable myocardial tissue. IABP is recommended by ACCF/AHA guideline (2013), which stated that "The use of IABP counterpulsation can be useful for patients with cardiogenic shock after STEMI who do not quickly stabilize with pharmacological therapy. (Class IIa recommendation, Level of evidence: A)" [16]. However, Sjauw et al. (2009) have challenged the existing general recommendations for the use of IABP in patients with ST-segment elevation myocardial infarction (STEMI) complicated by CS and have confirmed that IABP do not offer any advantage during PCI [10]. These findings were further supported by a well-powered, prospective, randomized clinical trial (IABP-SHOCK II trial) [12, 13], where they demonstrated that IABP did not reduce 30-day mortality or 12 month all-cause mortality in patients undergoing early revascularization for myocardial infarction complicated by cardiogenic shock. In addition, in patients with acute anterior STEMI without shock, no reduction in the infarct size was noted for IABP along with PCI as compared to PCI alone [23]. The current results are in agreement with the previous meta-analyses, $[8,10]$ where the benefit of adjunctive IABP therapy was not statistically significant in STEMI patients complicated by CS, and IABP did not show a significant reduction of mortality in 


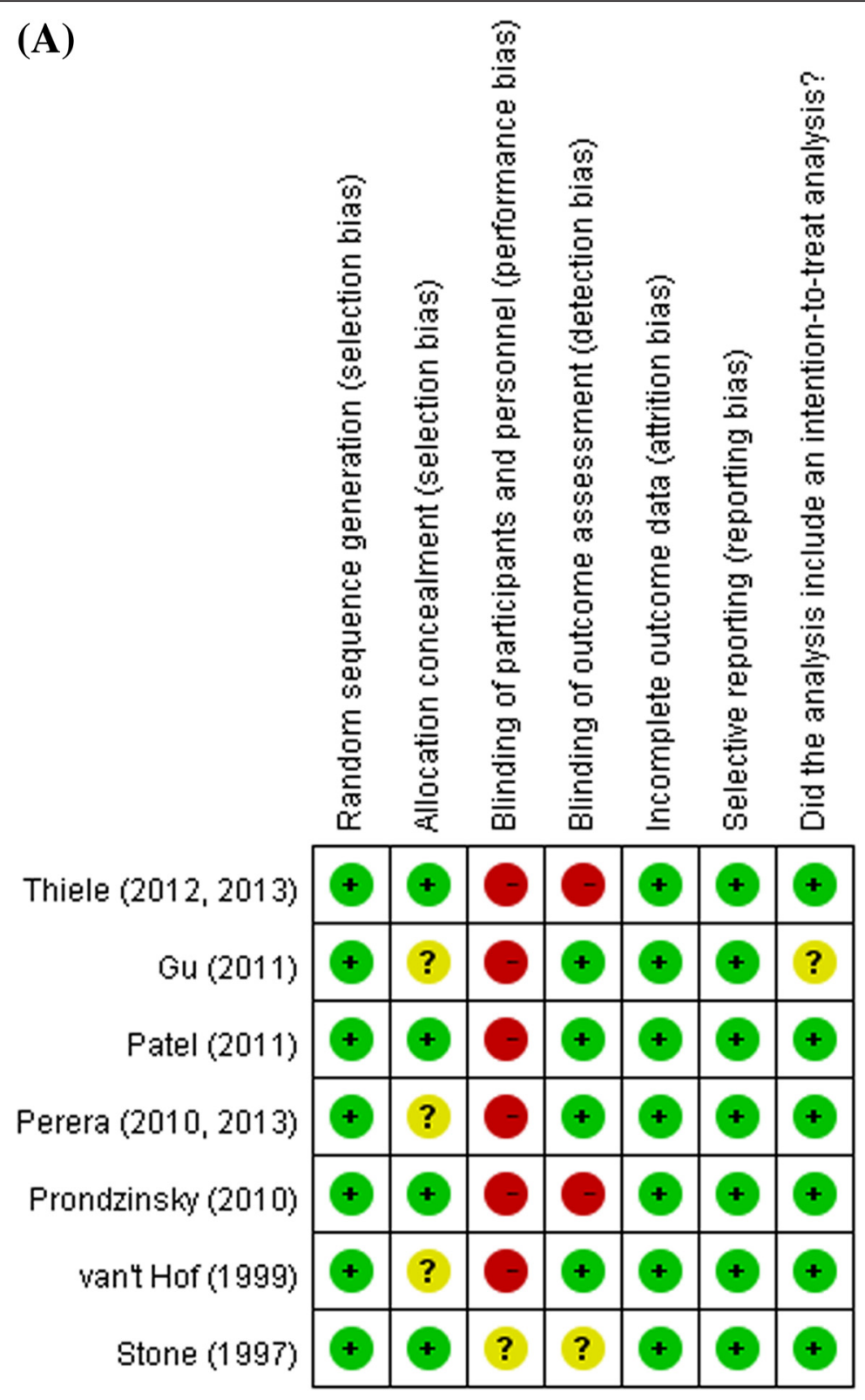

(B)

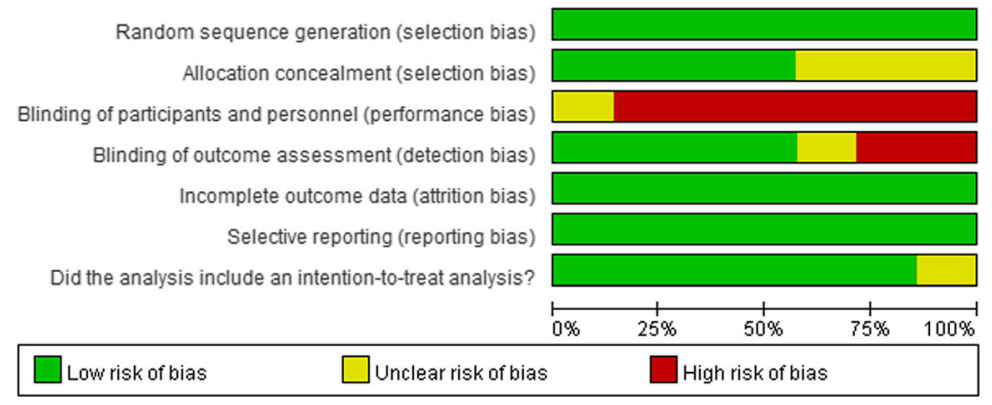

Fig. 5 Summary of quality assessment. a Risk of potential bias of individual study, $\mathbf{b}$ Risk of bias of all included studies 
patients with AMI and cardiogenic shock. In an updated ESC/EACTS Guidelines in 2014, routine use of IABP in patients with cardiogenic shock was not recommended (Class III recommendation, Level of evidence: A) [19]. IABP insertion should only be considered in patients with haemodynamic instability/cardiogenic shock due to mechanical complications (Class IIa recommendation, Level of evidence: C) [19].

The role of IABP support in the management of highrisk patients with AMI remains unclear. In a EUROTRANSFER registry of unselected patients with STEMI complicated by CS, the long term outcomes were similar between the high risk population with IABP and the low risk non-IABP patients, indicating that IABP may be effective in high risk patients [31]. Our result is consistent with the previous systematic review and meta-analysis that, in high-risk STEMI patients without CS, the majority of the studies could not demonstrate an efficacy benefit for IABP as compared to the control group in terms of in-hospital mortality, left ventricular ejection fraction, and rate of recurrent ischemia [20,32].

However, in patients with MI without CS, our metaanalysis showed a different result from the previous reports. A recent meta-analysis reported by Ahmad et al. found that IABP treatment had no statistically significant effect on mortality. This outcome was consistent when the articles were stratified by the presence or absence of CS [33]. A meta-analysis of six randomized trials concluded that IABP did not reduce all-cause death [34]. In a systematic review including randomized controlled trials published between 1981 and 2011, the majority of the studies could not demonstrate a beneficial effect of IABP therapy in patients with STEMI without CS [32]. Moreover, a retrospective analysis on the role of IABP in patients with acute MI without CS also found no difference in the in-hospital rate of cardiac death among patients who received IABP at the time of their coronary revascularization and the control group [35]. However, we found that IABP may reduce 30-day and 6-month mortality rate in patients with MI, but without CS. This is in agreement with a systematic review reported by Ye et al. where they reported that while IABP did not reduce mortality within 2 months and 6-12 months of intervention in AMI patients with CS, but it can reduce 6-12 month mortality in patients with AMI without CS [36]. Since we only included two RCTs in this subgroup, the clinical benefit of IABP in patients with acute MI without CS remains to be explored further in future studies.

Though IABP did not offer any major advantage during primary $\mathrm{PCI}$, it was effective as an adjunctive therapy to thrombolysis in patients with MI. Subgroup analysis even showed that, in patients with high-risk PCI without CS, IABP had higher odds of 30-day bleeding than those without IABP. Correspondingly, we did not observe any difference in the secondary outcomes like, 30-day mortality rate, 6-month mortality, 30-day reinfarction rate, 30 -day revascularization rate, or 30-day stroke rate between the IABP and the control groups. The metaanalysis reported by Cassese et al. had similar conclusion that IABP significantly reduced recurrent myocardial ischemia and increased the risk of bleeding [34]. The metaanalysis reported by Bahekar et al. also found that IABP significantly increased the risk of moderate to major bleeding [20]. Major bleeding associated with IABP, thus requiring increased transfusion, was also demonstrated in retrospective studies [35]. For revascularization rate after treatment, the meta-analysis reported by Sjauw et al. found that IABP showed a significantly higher revascularization rate compared to patients without support [10].

Though the majority of the recent reviews had failed to demonstrate a survival benefit for IABP, it was shown to have some beneficial effect on hemodynamic parameters, like cardiac index, mean arterial pressure, and pulmonary capillary wedge pressure [8]. It has been suggested that the use of IABP should be reserved for patients with severe hemodynamic compromise [29]. However, it should be noted that the improved hemodynamic status does not always translate into improved survival outcomes. In a recent commentary, Grieshaber and colleagues have suggested that IABP might have a greater effect in patients with reduced coronary perfusion and those with severely reduced left ventricular function, like in patients with AMI who need to be temporized prior to cardiac bypass surgery [7]. We did not analyze the hemodynamic parameters due to the limited number of data available in our included studies.

The current meta-analysis is an updated review of the available data on the utility of IABP during PCI. However, there are several limitations to our analysis, including the limited number of included studies in each subgroup and the heterogeneity in patient characteristics among the studies. The publication bias is difficult to interpret due to the limited number of included studies. Furthermore, there is a potential bias resulting from the inadequate blinding of patients and the study personnel.

\section{Conclusions}

The included RCTs demonstrate that IABP may reduce 30-day and 6-month mortality rate in patients with MI but without CS. In addition, for the patients with high risk PCI without $C S$, receiving IABP may have higher 30-day bleeding rate in compared to those without IABP. No clinical benefit of IABP was demonstrated in patients suffering high-risk PCI without CS and AMI complicated with CS. Future studies comprising of large, multicentric, prospective randomized trials should be undertaken to validate the current data and also to confirm or disprove its efficacy in patients with different 
diagnosis, including patients with high to moderate risk of CS and patients with AMI with and without CS.

\section{Abbreviations}

AMl, acute myocardial infarction; $C A B G$, coronary artery bypass graft; $C S$, cardiogenic shock; IABP, intra-aortic balloon pump; MI, myocardial infarction; $\mathrm{PCl}$, percutaneous coronary intervention; STEMI, ST-segment elevation myocardial infarction

\section{Acknowledgements}

None.

\section{Funding}

No funding.

\section{Availability of data and materials}

Data were retrieved from articles found in Pubmed, Medline, Cochrane and EMBASE, and summarized in Tables 1,2 and 3.

\section{Authors' contributions}

All authors guaranteed the integrity of the entire study. XYZ, YW, YC and XW designed the study and showed study concepts. XYZ, YW and ZGZ held the literature research. XYZ, YW, YC and XW acquired the data. XYZ, LC and JL analyzed the statistics. XYZ and YW put forward the definition of intellectual content. XYZ prepared, edited and revised the manuscript. All authors read and approved the final manuscript.

\section{Competing interests}

The authors declare that they have no competing interests.

\section{Consent for publication}

Not applicable.

\section{Ethics approval and consent to participate}

Not applicable.

Received: 10 June 2015 Accepted: 24 June 2016

Published online: 08 July 2016

\section{References}

1. Hochman JS, Sleeper LA, Webb JG, Sanborn TA, White HD, Talley JD, et al. Early revascularization in acute myocardial infarction complicated by cardiogenic shock. SHOCK Investigators. Should we emergently revascularize occluded coronaries for cardiogenic shock. N Engl J Med. 1999;341:625-34.

2. Goldberg RJ, Makam RC, Yarzebski J, McManus DD, Lessard D, Gore JM. Decade Long Trends (2001-2011) in the Incidence and Hospital Death Rates Associated with the In-Hospital Development of Cardiogenic Shock after Acute Myocardial Infarction. Circ Cardiovasc Qual Outcomes. 2016.

3. White JM, Ruygrok PN. Intra-aortic balloon counterpulsation in contemporary practice - where are we? Heart Lung Circ. 2015;24:335-41.

4. Romeo F, Acconcia MC, Sergi D, Romeo A, Muscoli S, Valente S, et al. The outcome of intra-aortic balloon pump support in acute myocardial infarction complicated by cardiogenic shock according to the type of revascularization: a comprehensive meta-analysis. Am Heart J. 2013;165:679-92.

5. Kantrowitz A, Tjonneland S, Freed PS, Phillips SJ, Butner AN, Sherman Jr JL. Initial clinical experience with intraaortic balloon pumping in cardiogenic shock. JAMA. 1968;203:113-8.

6. Cohen M, Urban P, Christenson JT, Joseph DL, Freedman Jr RJ, Miller MF, et al. Intra-aortic balloon counterpulsation in US and non-US centres: results of the Benchmark Registry. Eur Heart J. 2003;24:1763-70.

7. Grieshaber P, Niemann B, Roth P, Boning A. Prophylactic intra-aortic balloon counterpulsation in cardiac surgery: It is time for clear evidence. Crit Care. 2014;18:662.

8. Unverzagt S, Buerke M, de Waha A, Haerting J, Pietzner D, Seyfarth M, et al. Intra-aortic balloon pump counterpulsation (iabp) for myocardial infarction complicated by cardiogenic shock. Cochrane Database Syst Rev. 2015;3, CD007398.

9. Barron HV, Every NR, Parsons LS, Angeja B, Goldberg RJ, Gore JM, et al. The use of intra-aortic balloon counterpulsation in patients with cardiogenic shock complicating acute myocardial infarction: data from the national registry of myocardial infarction 2. Am Heart J. 2001;141:933-9.
10. Sjauw KD, Engstrom AE, Vis MM, van der Schaaf RJ, Baan Jr J, Koch KT, et al. A systematic review and meta-analysis of intra-aortic balloon pump therapy in st-elevation myocardial infarction: should we change the guidelines? Eur Heart J. 2009:30:459-68.

11. Patterson T, Perera D, Redwood SR. Intra-aortic balloon pump for high-risk percutaneous coronary intervention. Circ Cardiovasc Interv. 2014;7:712-20.

12. Thiele H, Zeymer U, Neumann FJ, Ferenc M, Olbrich HG, Hausleiter J, et al. Intraaortic balloon support for myocardial infarction with cardiogenic shock. N Engl J Med. 2012;367:1287-96.

13. Thiele H, Zeymer U, Neumann FJ, Ferenc M, Olbrich HG, Hausleiter J, et al. Intra-aortic balloon counterpulsation in acute myocardial infarction complicated by cardiogenic shock (iabp-shock ii): final 12 month results of a randomised, open-label trial. Lancet. 2013;382:1638-45.

14. Buerke M, Prondzinsky R, Lemm H, Dietz S, Buerke U, Ebelt H, et al. Intra-aortic balloon counterpulsation in the treatment of infarction-related cardiogenic shock-review of the current evidence. Artif Organs. 2012;36(6):505-11.

15. Anderson JL, Adams CD, Antman EM, Bridges CR, Califf RM, Casey Jr DE, et al. 2011 ACCF/AHA Focused Update Incorporated Into the ACC/AHA 2007 guidelines for the management of patients with unstable angina/non-STelevation myocardial infarction: a report of the American College of Cardiology Foundation/American Heart Association Task Force on Practice Guidelines. Circulation. 2011:123(18):e426-579.

16. O'Gara PT, Kushner FG, Ascheim DD, Casey Jr DE, Chung MK, de Lemos JA, et al. 2013 ACCF/AHA guideline for the management of ST-elevation myocardial infarction: a report of the American College of Cardiology Foundation/American Heart Association Task Force on Practice Guidelines. Circulation. 2013;127:e362-425.

17. Tamis-Holland JE, O'Gara P. Highlights from the 2013 ACCF/AHA guidelines for the management of ST-elevation myocardial infarction and beyond. Clin Cardiol. 2014;37:252-9.

18. Van de Werf F, Bax J, Betriu A, Blomstrom-Lundqvist C, Crea F, Falk V, et al. Management of acute myocardial infarction in patients presenting with persistent st-segment elevation: the task force on the management of st-segment elevation acute myocardial infarction of the european society of cardiology. Eur Heart J. 2008:29:2909.

19. Windecker S, Kolh P, Alfonso F, Collet JP, Cremer J, Falk V, et al. 2014 ESC/ EACTS Guidelines on myocardial revascularization: The Task Force on MyocardialRevascularization of the European Society of Cardiology (ESC) and the European Association for Cardio-Thoracic Surgery (EACTS) developed with the special contribution of the European Association of Percutaneous Cardiovascular Interventions (EAPCI). Eur Heart J. 2014;35:2541-619.

20. Bahekar A, Singh M, Singh S, Bhuriya R, Ahmad K, Khosla S, et al. Cardiovascular outcomes using intra-aortic balloon pump in high-risk acute myocardial infarction with or without cardiogenic shock: a meta-analysis. J Cardiovasc Pharmacol Ther. 2012;17:44-56.

21. Liberati A, Altman DG, Tetzlaff J, Mulrow C, Gotzsche PC, loannidis JP, et al. The prisma statement for reporting systematic reviews and meta-analyses of studies that evaluate health care interventions: explanation and elaboration. Ann Intern Med. 2009;151:W65-94.

22. Higgins JGS. Cochrane handbook for systematic reviews of interventions version 5.1. 0 [updated march 2011]. Chichester, West Sussex: The Cochrane Collaboration; 2011

23. Patel MR, Smalling RW, Thiele H, Barnhart HX, Zhou Y, Chandra P, et al. Intra-aortic balloon counterpulsation and infarct size in patients with acute anterior myocardial infarction without shock: the crisp ami randomized trial. JAMA. 2011;306:1329-37.

24. Gu J, Hu W, Xiao H, Feng X, Song Z, Chen Y, et al. Prophylactic intra-aortic balloon pump reduces c-reactive protein levels and early mortality in high-risk patients undergoing percutaneous coronary intervention. Acta Cardiol. 2011;66:499-504.

25. Stone GW, Marsalese D, Brodie BR, Griffin JJ, Donohue B, Costantini C, et al. A prospective, randomized evaluation of prophylactic intraaortic balloon counterpulsation in high risk patients with acute myocardial infarction treated with primary angioplasty. Second primary angioplasty in myocardial infarction (pami-ii) trial investigators. J Am Coll Cardiol. 1997;29:1459-67.

26. Perera D, Stables R, Clayton T, De Silva K, Lumley M, Clack L, et al. Long-term mortality data from the balloon pump-assisted coronary intervention study (bcis-1): a randomized, controlled trial of elective balloon counterpulsation during high-risk percutaneous coronary intervention Circulation. 2013;127:207-12. 
27. Perera D, Stables R, Thomas M, Booth J, Pitt M, Blackman D, et al. Elective intra-aortic balloon counterpulsation during high-risk percutaneous coronary intervention: a randomized controlled trial. JAMA. 2010;304:867-74.

28. Prondzinsky R, Lemm H, Swyter M, Wegener N, Unverzagt S, Carter JM, et al. Intra-aortic balloon counterpulsation in patients with acute myocardial infarction complicated by cardiogenic shock: the prospective, randomized iabp shock trial for attenuation of multiorgan dysfunction syndrome. Crit Care Med. 2010;38:152-60.

29. van 't Hof AW, Liem AL, de Boer MJ, Hoorntje JC, Suryapranata H, Zijlstra F. A randomized comparison of intra-aortic balloon pumping after primary coronary angioplasty in high risk patients with acute myocardial infarction. Eur Heart J. 1999;20:659-65.

30. Sutton AJ, Duval SJ, Tweedie RL, Abrams KR, Jones DR. Empirical assessment of effect of publication bias on meta-analyses. BMJ. 2000;320:1574-7.

31. Dziewierz A, Siudak Z, Rakowski T, Kleczynski P, Zasada W, Dudek D. Impact of intra-aortic balloon pump on long-term mortality of unselected patients with st-segment elevation myocardial infarction complicated by cardiogenic shock. Postepy Kardiol Interwencyjnej. 2014;10:175-80.

32. de Waha S, Desch S, Eitel I, Fuernau G, Lurz P, de Waha A, et al. What is the evidence for IABP in STEMI with and without cardiogenic shock? Ther Adv Cardiovasc Dis. 2012;6:123-32.

33. Ahmad Y, Sen S, Shun-Shin MJ, Ouyang J, Finegold JA, Al-Lamee RK, et al. Intra-aortic balloon pump therapy for acute myocardial infarction: a meta-analysis. JAMA Intern Med. 2015;175:931-9.

34. Cassese S, de Waha A, Ndrepepa G, Ranftl S, King L, Schömig A, et al. Intra-aortic balloon counterpulsation in patients with acute myocardial infarction without cardiogenic shock. A meta-analysis of randomized trials. Am Heart J. 2012;164:58-65.e1.

35. Mahmoudi M, Hauville C, Gaglia Jr MA, Sardi G, Torguson R, Xue Z, Satler LF, Suddath WO, Pichard AD, Waksman R. The impact of intra-aortic balloon counter-pulsation on in-hospital mortality in patients presenting with anterior ST-elevation myocardial infarction without cardiogenic shock. Cardiovasc Revasc Med. 2012;13:328-30.

36. Ye L, Zheng M, Chen Q, Li G, Deng W, Ke D. Effects of intra-aortic balloon counterpulsation pump on mortality of acute myocardial infarction. PLoS One. 2014;9, e108356.

\section{Submit your next manuscript to BioMed Central and we will help you at every step:}

- We accept pre-submission inquiries

- Our selector tool helps you to find the most relevant journal

- We provide round the clock customer support

- Convenient online submission

- Thorough peer review

- Inclusion in PubMed and all major indexing services

- Maximum visibility for your research

Submit your manuscript at www.biomedcentral.com/submit

) Biomed Central 